\title{
Gratitude, Forgiveness and Religiosity- A Comparative Study
}

\author{
Mansi Sharma ${ }^{1 *}$
}

\section{ABSTRACT}

India is home to diverse cultures and religious practices since time immemorial. India has been a secular state which preaches freedom of religious beliefs and keeps the cultural identity of the residents of the country intact. Psychologists and researchers who study religion want to understand what religion would mean psychologically. To study religion psychologically researchers usually rely on empirical and scientific approach. The present research is an attempt to understand that how gratitude and forgiveness affects religiosity which is a major way of leading a life in India. The present study was conducted to understand the effect of gratitude and forgiveness on religiosity with an in- depth attempt to study the differences on gratitude and forgiveness across religious groups (Hindus, Muslims, Sikhs and Christians). The sample included of 140 participants, 35 each of which belonged to Hinduism, Islam, Sikhism and Christianity. A correlational analysis was run to understand the relationship of religiosity and gratitude, religiosity and forgiveness and gratitude and forgiveness. It was found that no significant correlation was depicted among the same.

\section{Keywords: Gratitude, Forgiveness, Religiosity}

I ndia is home to diverse cultures and religious practices since time immemorial. India has been a secular state which preaches freedom of religious beliefs and keeps the cultural identity of the residents of the country intact.

Evidences pertaining to the religious depiction dates back to the prehistoric region in forms of dancing rituals on rocks in the form of paintings and carvings. Neolithic tribes near the Indus valley buried the dead and showed spiritual effects of afterlife. The Harappan civilization that existed from 3300 to $1400 \mathrm{BCE}$ was located on the Indus and GhaggarHakra river valleys, shows archeological evidences that they must have worshiped a goddess symbolising fertility and growth.

Psychologists and researchers who study religion want to understand what religion would mean psychologically. To study religion psychologically researchers usually rely on empirical and scientific approach.

\section{Definition of Religion}

"[Religion is] the belief in Spiritual Beings" (Edward B Tylor, Primitive Culture)

${ }^{1}$ Counselling Psychologist, Uttar Pradesh, India

*Corresponding Author

Received: April 14, 2021; Revision Received: May 05, 2021; Accepted: May 20, 2021

(C) 2021, Sharma M.; licensee IJIP. This is an Open Access Research distributed under the terms of the Creative Commons Attribution License (www.creativecommons.org/licenses/by/2.0), which permits unrestricted use, distribution, and reproduction in any Medium, provided the original work is properly cited. 
"Religion, like culture, is a symbolic transformation of experience." (Thomas F. O'Dea, The Sociology of Religion)

"[Religion is] the feelings, acts, and experiences of individual men in their solitude, so far as they apprehend themselves to stand in relation to whatever they may consider the divine." (William James, The Varieties of Religious Experience)

"[Religion is] a system of symbols (creed, code, cultus) by means of which people (a community) orient themselves in the world with reference to both ordinary and extraordinary powers, meanings, and values." (Catherine L. Albanese, America: Religions and Religion)

To understand how religion affects the cultural and social contexts of individuals, we need to understand the following major religious practiced in India-

\section{HINDUISM}

Branches of Hinduism differ greatly from each other, but maintain the fact that "god is one." It would be correct to say that common to somehow or somewhere, all religious Hindus is a belief "in a reality that transcends the mundane, empirical, or phenomenal world" Puhakka, (1995)

The ultimate essence of Hinduism lies in the fact that though there might exist infinite number of gods; they are all AVTARS of one, supreme divine light. Hinduism maintains that god has existed in various human forms only to preach about the life lessons important for human being's survival, but god is still NIRAKAR. Thus, the universe creator (LORD BRAHMA), the provider (LORD VISHNU), the ultimate destroyer (LORD SHIVA) - the trio is the essential pillars to the belief of the religion of the Hinduism.

The ultimate goal of the Hindu moral life is spiritual liberation, or the achievement of unity with the Brahman. To achieve this goal, one must initially also strive toward achieving the lower ideals of wealth, pleasure, and ethical merit. Ultimately, however, such goals must be transcended to achieve union with the Supreme Being, and this is accomplished through four spiritual paths:

- Bhakti yoga- The path of devotion: This aspect talks about showing devotion towards god/goddesses so that the ultimate emotion of love and compassion can be achieved. Also, religious people show bhakti by reciting hymns, bhajans to achieve the path of fulfillment.

- Jnana yoga- The path of knowledge: To attain the knowledge of what is right and wrong, to undo the wrong and to initiate the right through leanings, and attainment of knowledge brings out the essence of this path to attain the ultimate salvation. The Adishankara states that only if one is self -aware, he can destroy all the enemies through knowledge and courage

- Karma yoga-The path of work: This path stresses upon the importance of karmawork and dharma- the duty of an individual towards being fair and respectful towards the teachers, the children. The Hinduism aspect focuses on the true service to god without expecting any rewards.

- Raja yoga- the path of intellectual realization: While the mindfulness concept to achieve concentration and enjoy a stress free life was adapted by the western culture, the Indians focus majorly to attain the path of self -actualization through the 
enchantment of mantras and dhwanis Needless to say while the techniques can differ, the main aim is enlightenment and becoming the best possible human version of oneself.

\section{ISLAM}

Islam is one of the most widely practiced religions in the world. The religion applies usually to all the Muslims across the globe. The Muslims rely majorly on the holy teachings of the Quran. Just like other religions, Islam too talks about the importance of helping those in need, being truthful towards the teachings of Allah. The idea of Islam or Islamiyat talks about the five pillars.

- SHAHADA- Believing in the fact that there is no other god than Allah and practicing the messages and teachings of Prophet Muhammad (PBUH).

- SALAH- For the act of courage and righteousness a proper schedule of praying 5 times a day is crucial.

- ZAKAT- Religious followers of Islam are supposed to share their wealth in terms of charity with those who can't afford a better life. Sharing their wealth with the needy makes them even more close to Allah.

- SAWM-Fasting during the holy period of RAMADAN, Muslims are supposed to exercise restrain from the worldly pleasures of life.

- HAJJ- the followers if they can afford and are healthy have to visit the pilgrimage of MECCA.

\section{CRISTIANITY}

The development of Christianity can be traced down to the divine birth of Lord Jesus Christ some 2000 years back in the present day Israel in a humble Jewish familial setup. The followers of Christianity believed that Jesus Christ was a son of the divine light sent on the earth to enlighten people about the various catholic teachings.

Talking about its followers Christianity is undoubtedly the biggest religion in the world. The followers rely largely on the teachings of Lord Jesus Christ. The bible is the sacred text of the Christians. A lot of followers interpret the text conservatively and literally while others follow a symbolic and more liberal meaning of the text.

\section{Beliefs of Christianity}

- Christians only believe that there is one god. They are monotheistic, and they believe that the heaven on the earth was created by god himself.

- Christians also believe that god sent his own son, lord Jesus the messiah to save the world from its atrocities.

- They also believe that Jesus would come back to earth which will be the second coming.

- The sacred bible follows certain images which teaches the important preaching of lord Jesus,

- The holy cross is the symbol of Christianity.

\section{SIKHISM}

Various sources and texts assume that Sikhism is a monotheistic religious belief. The belief or religious ideology was introduced by Guru Nanak Dev around the year 1469. The religion flourished under his supervision with the help of hymns or shabads which promoted manifestations, righteousness and spirituality towards god. These shabads are compiled into 


\section{Gratitude, Forgiveness and Religiosity- A Comparative Study}

Siri Guru Granth Sahib. These teachings are not only the original contribution of the influential Sikh proponents but also inspired from the teachings of Hinduism and Islam. Further the compilation of the Sri Guru Granth Sahib was constructed and compiled by the Sikh gurus themselves.

It was in 1699 when the tenth guru, Guru Gobind Singh established the Khalsa and this gave the Sikh followers a distinct identification which took place on the auspicious day of vaisakhi.

It is a popular belief that before his demise, Sri Guru Gobind Singh declared the Guru Granth Sahib as the ultimate holy book for Sikh followers.so if asked a Sikh would maintain that they have 11 gurus ( the 10 gurus and 1, the holy GURU GRANTH SAHIB)

Some basic ideological beliefs of the Sikhs also include that god is formless thus neither he can be not created nor be destroyed. Salvation or liberation can be attained through preaching the shabads or the hymns and the main aim is to focus on one god only through the process of prayer, meditation, or reading the holy text, Guru Granth Sahib.

Khalsa is noted as the military unit of the Sikh followers. Every Sikh is supposed to follow or imbibe the essence of $5 \mathrm{Ks}$ - having uncut hair for both males and females called as $\mathrm{KESH}$, which are supposed to be covered by turban or a scarf, the KANGHA symbolizes the cleanliness, the underwear the KACHERA which acts as a reminder to stay away from lust, sexual greed and attachment, a small sword KIRPAN purely used as a self defence equipment and lastly KADA which denoted the oneness to the Guru and has no beginning or end.

\section{GRATITUDE}

When we talk about gratitude, its meaning in positive psychology is usually different in what individuals are grateful for in their everyday life. Gratitude is not an everyday action, it's a way of living life more than an ideology.

Researchers have tried to define the concept of gratitude for a better understanding of its complexities-

(Sansone \& Sansone, 2010). States that being grateful means

"The appreciation of what is valuable and meaningful to oneself and represents a general state of thankfulness and/or appreciation"

From a research perspective, gratitude would mean,

"A social emotion that signals our recognition of the things others have done for us" according to Fox et al., (2015)

Researchers have also tried to formulate a definition based on a social concept which states that-

"Gratitude is a positively valenced emotion that can arise when another person - a benefactor - does something kind for the self (Algoe et al., 2016).

Dr.Robert Emmons (2003) talks about two stages of feeling a complete gratitude based experience.

First stage is experienced when we accept the goodness of gratitude in our lives. This is when we say yes to accepting and embracing our positive emotions. The second stage occurs

(c) The International Journal of Indian Psychology, ISSN 2348-5396 (e) | ISSN: 2349-3429 (p) | 969 
when we realize the fact that our outside forces are too enabling us to accept the force of gratitude.

Thus when the two stages of gratitude combine, we should be first able to identify the greatness that lies within us and then we must understand that it lies out of ourselves too, in other living creatures.

Gratitude is considered to be a selfless act which would also mean that acts of gratitude must be done without expecting anything in return. Further Dr. Emmons views gratitude in terms of its totality based on the completion of the above two stages.

\section{FORGIVENESS}

"Forgiveness says you are given another chance to make a new beginning."-Desmond Tutu.

In other terms, forgiveness means to let go of emotions that include anger, disgust, disappointment, revenge, and discontentment which we could have towards a person even if the person does not seeks or deserves our forgiveness.

When we as an individual forgive others, the intentions behind it need not necessarily being that of reconciling with the person. Sometimes we have to forgive the person (s) for our own inner peace. It is also a crucial aspect to understand forgiveness in its totality. Thus we can also mean that forgiveness deals more than the person being forgiven, it deals with our own selves.

The ability to forgive oneself for the mistakes, small or large, is essential for psychological wellbeing. Forgiving oneself relieves unpleasant feeling of guilt and shame. SelfForgiveness might be better seen as an honest acknowledgement of our capacity of making mistakes and accepting our fallible human nature.

In the present study, majority of participants have scored high on the Forgiving of Self subscale.

The items under this subscale consists statements like "With time I am understanding of myself for mistakes I've made", "Learning from bad things that I've done helps me get over them."

\section{REVIEW OF LITERATURE}

Jang et.al (2019) studied the relationship between religiousness and negative emotions among prisoners is applicable to inmates' sense of meaning of life and personal virtues along with if religiousness has a strong relationship with search for and meaning in life and forgiveness, gratefulness, and self-control among female than male inmates. Sample consisted of South African jail inmates. Findings showed that highly religious members showed decreased levels of gloomy emotions along with an improved sense of meaning and purpose in life as compared to their non-religious counterparts. Religiousness applies equally to both male and female inmates.

Kaur (2019) studies the effect of forgiveness, concept of god and thankfulness in mental health among followers of Sikhism sample was 70 males and 90 females. HFS, God Concept Scale, MHC-SF, Religious Commitment Inventory [RCI- 10], GQ-6 and Daily 
spiritual Experience Scale were administered. It was concluded that, the religious devotion showed a positive effect on mental health for the Sikhs.

Gratitude and forgiveness are studied as character strengths but majority of researches have been carried out among adults. Shourie and Kaur (2016) studied the alliance among being grateful, forgiving and wellbeing within adolescents. The sample was 125 boys and girls each. Results depicted that gratefulness and forgiveness were positively correlated with wellbeing. The study also formulated that gratitude and forgiveness showed positive correlation with life-fulfillment.

Charzyńska (2015) aimed to explore the gender variations in spiritual coping, forgiveness, and gratefulness and changes happening in these areas during a basic alcohol addiction treatment program. The study employed 56 men and women each, who had undergone a basic alcohol addiction treatment program. The Spiritual Coping scale, the Forgiveness Scale, and GQ-6 were administered. It was found that during the therapy, positive changes in spiritual coping was reported in both males and females, The increase in the level of moral values (excluding selfforgiveness) was evident in females. The study focuses on the need to take sex differences into consideration when employing spiritual elements in therapy.

In empirical evidence, Kausar (2018) tried to explore the alliance among gratitude and happiness in college going students. An existence of a relationship between gratitude and happiness was hypothesized. The sample comprised of 100 (50 boys and girls each) from various private \& public colleges of Lahore. For this Subjective Happiness Scale by Sonja and Lepper (1999) along with (GQ-6) were administered to predict happiness and appreciation in college going students. Pearson correlation, linear regression and student's ttest were used for analysis. Findings depicted a significant positive relationship among these variables. Gratitude was also established as a predictor of happiness among college going students. No significant gender-based variations were reported. The results apply well to the Pakistani youth tendencies.

Berthold, \& Ruch, (2014), aimed to study fulfillment with life and character strengths of nonreligious people vs. religious people. For this, life satisfaction (SWLS), character strengths (VIAIS) and the orientations to happiness (OTH) scales were used on a sample of 20,538 subjects. People with religious associations who also practiced their religion were found to be increasingly satisfied with their life \& scored higher on life of meaning than non-religious people. Also, religious people who practice their religion differed evidently from those who did not practiced their religion and non-religious people when assessed on various character strengths; they scored high on kindness, gratitude, love, forgiveness., hope, and spirituality. There were no significant discrepancies among religious and non- religious people. Together the findings show that individuals are positively affected from religious associations if they also practice their religion.

Ramirez et.al (2014) led an examination to expand the nature of living in subjects of more than 60 years with the assistance of a treatment dependent on positive brain research. For this a personal memory, absolution and appreciation preparing project was utilized. The example gathered was of 46 understudies matured from 60 to 93 yrs. Tension, general memory; despondency, life satisfaction, explicit recollections and abstract joy were evaluated. Results delineated that subjects who experienced the program (the trial gathering) showed a huge abatement in uneasiness and wretchedness and increment in the score of 
explicit recollections abstract satisfaction and life satisfaction contrasted with fake treatment gathering.

Satici, Uysal \& Akin (2014). led an examination on assessing the interlinking job of appreciation on the connection among absolution and retribution. Subjects for the investigation were 331 college understudies (185 females, 146 guys; matured 17 to 24 years), they filled the accompanying scales - Vengeance Scale, Trait Forgiveness Scale, and GQ-6. Results demonstrated that appreciation assumes a vital job of an encouraging component among absolution and vengeance. The outcomes show that appreciation assumes a key job in supporting prosperity of people.

\section{METHODOLOGY}

Aim: The present research is aimed to study Gratitude and Forgiveness as correlates to Religiosity.

\section{Objectives}

- To study the relationship between gratitude, forgiveness and religiosity.

- To study the difference between Hindus, Muslims, Sikhs and Christians on gratitude and forgiveness.

\section{Hypotheses}

- There will be a significant relationship between gratitude, forgiveness and religiosity.

- There will be a significant difference among Hindus, Muslims, Sikhs and Christians on gratitude and forgiveness.

\section{Sample}

- SIZE OF THE SAMPLE- 140

- AGE- 20-30 YEARS

- SEX- BOTH MALES AND FEMALES

Variables

- Gratitude

- Forgiveness

- Religiosity

\section{Description of The Tools Used}

1.The religiousness measure- was developed by Sethi and Seligman in 1993. It aims to assess religiosity among the participants of the research. It aims to assess and understand the overall religious practices, patterns and behavioral aftereffects thereafter. This 17 item tool is multidimensional in nature as it assesses three aspects of religiousness; religious hope, religious involvement and religious influence in daily life. Out of 17 items 2 items are not quantified for result evaluation as they ask about the religious or life preferences like whether the participant believes in god and whether they will marry someone of different religion. Even though the $r$ values were low, the results for validation came out to be significant due to the large sample size.

2.The GQ-6 Form- The GQ-6 is a short, self-report measure of the disposition to experience gratitude developed by Michael E. McCullough, Robert A. Emmons and Jo-Ann Tsang. Participants answer 6 items on a 1 to 7 scale $(1=$ "strongly disagree", $7=$ "strongly 
agree"). Two items are reverse-scored to inhibit response bias. The GQ-6 has good internal reliability, with alphas between .82 and .87 , and there is evidence that the GQ-6 is positively related to optimism, life satisfaction, hope, spirituality and religiousness, forgiveness, empathy and pro social behaviour, and negatively related to depression, anxiety, materialism and envy. The GQ-6 takes less than 5 minutes to complete, but there is no time limit.

3.Heartland Forgiveness Scale- Heartland Forgiveness Scale (HFS) is an 18-item, selfreport questionnaire that measures a person's dispositional forgiveness (i.e., the general tendency to be forgiving), rather than forgiveness of a particular event or person.).

\section{Procedure}

For the present study, participants falling under the age group of 20-30 years were approached personally for data collection. After taking their consent and informing them about the research, rapport was formed to make the participants comfortable. Participants were made ensure that their responses would be kept confidential, and there are neither right nor wrong responses. After this, questionnaires were handed over to the participants and instructions were read out from the manuals of each test. During the conduction, participant's doubts were clarified, and it was ensured that all the items in the questionnaire are answered by them. After completing the questionnaires, participants were thanked for their participation.

When data collection was completed, scoring was done as per the instructions in the manual, and the scores of each participant was added in the excel sheet.

Statistical Analysis-

Descriptive Statistics

ANOVA

\section{ANALYSIS OF RESULTS}

Table 1: Mean and Standard Deviation for Religiosity, Gratitude and Forgiveness across religions

\begin{tabular}{ll|l|l} 
& N & Mean & Std. Deviation \\
\hline Religiosity & 140 & 70.6357 & 4.71369 \\
\hline Gratitude & 140 & 30.7000 & 2.71076 \\
\hline forgiveness & 140 & 96.9071 & 4.02670 \\
\hline
\end{tabular}

Table: 2 Correlation between Religiosity and Gratitude

\begin{tabular}{llll} 
& & religiosity & gratitude \\
\hline religiosity & Pearson Correlation & 1 & .111 \\
\cline { 2 - 4 } & Sig. (2-tailed) & .193 \\
\hline gratitude & $\mathrm{N}$ & 140 & 140 \\
\cline { 2 - 4 } & Pearson Correlation & .111 & 1 \\
\hline & Sig. (2-tailed) & .193 & 140 \\
\hline
\end{tabular}

*No significant correlation was reported between religiosity and gratitude. 
Table 3: Correlation between Religiosity and Forgiveness

\begin{tabular}{llll} 
& & religiosity & forgiveness \\
\hline religiosity & Pearson Correlation & 1 & .062 \\
\cline { 2 - 4 } & Sig. (2-tailed) & .470 \\
\hline forgiveness & $\mathrm{N}$ & 140 & 140 \\
\cline { 2 - 4 } & Pearson Correlation & .062 & 1 \\
\cline { 2 - 4 } & Sig. (2-tailed) & .470 & 140 \\
\hline
\end{tabular}

*no significant correlation was reported between religiosity and forgiveness

Table 4: Correlation between Gratitude and Forgiveness

\begin{tabular}{llll} 
& & forgiveness & gratitude \\
\hline forgiveness & Pearson Correlation & 1 & -.132 \\
\cline { 2 - 4 } & Sig. (2-tailed) & 140 & 119 \\
\cline { 2 - 4 } & $\mathrm{N}$ & -.132 & 140 \\
\hline gratitude & Pearson Correlation & .119 & 1 \\
\cline { 2 - 4 } & Sig. (2-tailed) & 140 & 140 \\
\hline
\end{tabular}

*no significant correlation was reported between gratitude and forgiveness

**Hence the hypothesis of a positive relationship between religiosity, gratitude and forgiveness is rejected.

Table 5: Anova scores on Gratitude across religions

\begin{tabular}{lll|l|l|l} 
& Sum of Squares & df & Mean Square & \multicolumn{1}{l}{ F } & \multicolumn{1}{l}{ Sig. } \\
\hline Between Groups & 9.971 & 3 & 3.324 & .447 & .720 \\
\hline Within Groups & 1011.429 & 136 & 7.437 & & \\
\hline Total & 1021.400 & 139 & & & \\
\hline
\end{tabular}

*no significant difference was reported across religious groups when assessed on gratitude.

Table 6: Anova scores on Forgiveness across religions

\begin{tabular}{ll|l|l|l|l} 
& Sum of Squares & df & Mean Square & F & Sig. \\
\hline Between Groups & 63.850 & 3 & 21.283 & 1.322 & .270 \\
\hline Within Groups & 2189.943 & 136 & 16.103 & & \\
\hline Total & 2253.793 & 139 & & & \\
\hline
\end{tabular}

*no significant difference was reported across religious groups when assessed on forgiveness.

***Hence the hypothesis of a significant difference across religious groups on gratitude and forgiveness is rejected.

\section{DISCUSSION}

The present study was conducted to understand the effect of gratitude and forgiveness on religiosity with an in-depth attempt to study the differences on gratitude and forgiveness across religious groups (Hindus, Muslims, Sikhs and Christians). 
Psychologists and researchers who study religion want to understand what religion would mean psychologically. To study religion psychologically researchers usually rely on empirical and scientific approach.

According to (Thomas F. O'Dea, the Sociology of Religion)

"Religion, like culture, is a symbolic transformation of experience."

India is home to diverse cultures and religious practices since time immemorial. India has been a secular state which preaches freedom of religious beliefs and keeps the cultural identity of the residents of the country intact.

The ultimate goal of the Hindu moral life is spiritual liberation, or the achievement of unity with the Brahman. To achieve this goal, one must initially also strive toward achieving the lower ideals of wealth, pleasure, and ethical merit.

Islam is one of the most widely practiced religions in the world. The religion applies usually to all the Muslims across the globe. The Muslims rely majorly on the holy teachings of the Quran. Just like other religions, Islam too talks about the importance of helping those in need, being truthful towards the teachings of Allah.

Talking about its followers Christianity is undoubtedly the biggest religion in the world. The followers rely largely on the teachings of Lord Jesus Christ. The bible is the sacred text of the Christians. A lot of followers interpret the text conservatively and literally while others follow a symbolic and more liberal meaning of the text.

Some basic ideological beliefs of the Sikhs include that god is formless thus neither he can be not created nor be destroyed. Salvation or liberation can be attained through preaching the shabads or the hymns and the main aim is to focus on one god only through the process of prayer, meditation, or reading the holy text, Guru Granth Sahib.

When we talk about gratitude, its meaning in positive psychology is usually different in what individuals are grateful for in their everyday life. Gratitude is not an everyday action, it's a way of living life more than an ideology.

Researchers have tried to define the concept of gratitude for a better understanding of its complexities-

(Sansone \& Sansone, 2010). States that being grateful means

"The appreciation of what is valuable and meaningful to oneself and represents a general state of thankfulness and/or appreciation"

"A recognition that we could not be who we are life without the contribution of others." He believes that a person can be grateful even in the times of adversity. People who experience gratitude in such times are reportedly much happier than those who do not and are less susceptible to negative emotions. Emmons says "It is this presence of thankfulness in trying times that enables us to conclude that gratitude is not simply a form of positive thinking or happy-ology but rather a deep and abiding recognition and acknowledgement that goodness exists under even the worst that life offers."

"Forgiveness says you are given another chance to make a new beginning."- Desmond Tutu.

(c) The International Journal of Indian Psychology, ISSN 2348-5396 (e) | ISSN: 2349-3429 (p) | 975 


\section{Gratitude, Forgiveness and Religiosity- A Comparative Study}

In other terms, forgiveness means to let go of emotions that include anger, disgust, disappointment, revenge, and discontentment which we could have towards a person even if the person does not seeks or deserves our forgiveness.

When we as an individual forgive others, the intentions behind it need not necessarily being that of reconciling with the person. Sometimes we have to forgive the person (s) for our own inner peace. It is also a crucial aspect to understand forgiveness in its totality. Thus we can also mean that forgiveness deals more than the person being forgiven; it deals with our own selves.

Several studies have been conducted to study religiousness, gratitude and forgiveness.

Tsang et.al (2012) contended that however appreciation is an indispensable part of religion, minimal observational information is accessible on the coalition among appreciation and religion. Results demonstrated that inborn religiosity was unequivocally connected to being appreciative. Natural religiosity was likewise emphatically connected to self-revealed inspiration by offering thanks, without support.

Ilbay \& Sarıçam (2015) aimed to investigate the alliance among forgiveness, gratitude, and psychological vulnerability. Results illustrated that there were positive relationships between forgiveness, gratitude, and psychological vulnerability. Indices of (SEM) showed that forgiveness was strongly predicted by gratitude and psychological vulnerability.

Jang et.al (2019) studied the relationship between religiousness and negative emotions among prisoners is applicable to inmates' sense of meaning of life and personal virtues along with if religiousness has a strong relationship with search for and meaning in life and forgiveness, gratefulness. Findings showed that highly religious members showed decreased levels of gloomy emotions along with an improved sense of meaning and purpose in life as compared to their non-religious counterparts.

To assess religiosity, the religiousness measure by Sethi and Seligman was used, it is a 17 item scale used to measure religious attitudes and attributes. 2 items out of 17 are categorical items to understand the personal preferences of the participants (will they marry someone of other religion and if they believe in god).

To measure gratitude GQ-6 from was used. It is a 6 item questionnaire which attempts to measure gratefulness of participants on various aspects of life and related to people in general. Items 3 and 6 are reverse scored and the test is a 7 point likert scale.

To compute the level of forgiveness Heartland forgiveness scale was used. It is an 18 item scale on a 7 point likert scale to assess forgiveness of the participants in situations of daily life.

These three scales have substantial reliability and validity and are widely used.

The sample included of 140 participants, 35 each of which belonged to Hinduism, Islam, Sikhism and Christianity. A correlational analysis was run to understand the relationship of religiosity and gratitude, religiosity and forgiveness and gratitude and forgiveness. It was found that no significant correlation was depicted among the same.

Tsang et.al (2012) contended that however appreciation is an indispensable part of religion, minimal observational information is accessible on the coalition among appreciation and

(c) The International Journal of Indian Psychology, ISSN 2348-5396 (e)| ISSN: 2349-3429 (p) | 976 
religion. Results showed that the religious sample had a marginal main effect, facilitating pro social behavior but not gratitude.

Further analysis showed that no significant relationship existed between Hindus, Muslims, Christians and Sikhs when tested on gratitude and forgiveness, thus we can say that in this population sample individuals of these religions scored similar on gratitude and forgiveness.

\section{CONCLUSION}

The present study was conducted to understand the effect of gratitude and forgiveness on religiosity with an attempt to study the differences on gratitude and forgiveness across religious groups (Hindus, Muslims, Sikhs and Christians).

The sample included of 140 participants, 35 each of which belonged to Hinduism, Islam, Sikhism and Christianity. A correlational analysis was run to understand the relationship of religiosity and gratitude, religiosity and forgiveness and gratitude and forgiveness. It was found that no significant correlation was depicted among the same.

Tsang et.al (2012) contended that however appreciation is an indispensable part of religion, minimal observational information is accessible on the coalition among appreciation and religion. Results showed that the religious sample had a marginal main effect, facilitating pro social behavior but not gratitude.

Further analysis showed that no significant relationship existed between Hindus, Muslims, Christians and Sikhs when tested on gratitude and forgiveness, thus we can say that in this population sample individuals of these religions scored similar on gratitude and forgiveness.

\section{LIMITATIONS}

The limitations of my study were that there was a limited sample and these recordings were not done in the extreme controlled conditions. So, there might be a little manipulation possible with the sample performance. Also, the researcher has just included the sample from the Delhi NCR region. A data collection based across India or at least major states would have refined the findings of the study.

The age group is 20-30 years where religiosity may not have a direct influence on how individuals inculcate gratitude and forgiveness in their lives. People may be religious but may not be thankful or forgiving in their usual nature.

\section{Suggestions}

A variable of resilience can also be added to better understand the interplay of religiosity, gratitude, forgiveness and resilience in individuals with a larger sample size for concrete findings.

\section{REFERENCES}

Berthold, A., \& Ruch, W. (2014). Satisfaction with life and character strengths of nonreligious and religious people: it's practicing one's religion that makes the difference. Frontiers in Psychology, 5, 876.

Charzyńska, E. (2015). Sex differences in spiritual coping, forgiveness, and gratitude before and after a basic alcohol addiction treatment program. Journal of religion and health, 54(5), 1931-1949. 
Gupta, N., \& Kumar, S. (2015). Significant predictors for resilience among a sample of undergraduate students: Acceptance, forgiveness and gratitude. Indian Journal of Health \& Wellbeing, 6(2).

Jang, S. J., Johnson, B. R., Anderson, M. L., \& Booyens, K. (2019). The Effect of Religion on Emotional Well-Being Among Offenders in Correctional Centers of South Africa: Explanations and Gender Differences. Justice Quarterly, 1-28.

Jordan A. Booker \& Julie C. Dunsmore (2016) Profiles of wisdom among emerging adults: Associations with empathy, gratitude, and forgiveness, The Journal of Positive Psychology, 11:3, 315-325.

Kaur, J. (2019). Role of Forgiveness, Daily Spiritual Experience, Religious Commitment, God Concept and Gratitude in Mental Health among Sikh Religious Followers (Doctoral dissertation).

Kausar, R. (2018). Relationship between gratitude and happiness in college students. Indian Journal of Positive Psychology, 9(1), 109-113.

Kirmani, M. N. (2015). Gratitude, forgiveness and subjective well-being among college going students. International Journal of Public Mental Health and Neurosciences, 2(2), 1-10.

Kong, F., Ding, K., \& Zhao, J. (2015). The relationships among gratitude, self-esteem, social support and life satisfaction among undergraduate students. Journal of Happiness Studies, 16(2), 477-489.

Kumari, M. H., \& Madnawat, A. V. S. (2016). Gratitude and forgiveness as a predictor of well-being among female college students. Indian Journal of Positive Psychology, 7(4), 511.

Ramírez, E., Ortega, A. R., Chamorro, A., \& Colmenero, J. M. (2014). A program of positive intervention in the elderly: Memories, gratitude and forgiveness. Aging \& mental health, 18(4), 463-470.

Satici, S. A., Uysal, R., \& Akin, A. (2014). Forgiveness and Vengeance: The Mediating Role of Gratitude. Psychological Reports, 114(1), 157-168.

Sharma, S., \& Singh, K. (2019). Religion and well-being: the mediating role of positive virtues. Journal of religion and health, 58(1), 119-131.

Shourie, S., \& Kaur, H. (2016). Gratitude and forgiveness as correlates of well-being among adolescents. Indian Journal of Health \& Wellbeing, 7(8).

Szcześniak, M., Bielecka, G., Bajkowska, I., Czaprowska, A., \& Madej, D. (2019). Religious/Spiritual Struggles and Life Satisfaction among Young Roman Catholics: The Mediating Role of Gratitude. Religions, 10(6), 395.

Tsang, J.-A., Schulwitz, A., \& Carlisle, R. D. (2012). An experimental test of the relationship between religion and gratitude. Psychology of Religion and Spirituality, $4(1), 40-55$.

\section{Acknowledgement}

The author(s) appreciates all those who participated in the study and helped to facilitate the research process.

\section{Conflict of Interest}

The author(s) declared no conflict of interest.

How to cite this article: Sharma M. (2021). Gratitude, Forgiveness and Religiosity- A Comparative Study. International Journal of Indian Psychology, 9(2), 966-978. DIP:18.01.100.20210902, DOI:10.25215/0902.100 